\title{
A Comparative Study of Electrocardiographic and Echocardiographic Evidence of Left Ventricular Hypertrophy
}

\author{
${ }^{1}$ Gurinder Mohan, ${ }^{2}$ Ranjeet Kaur, ${ }^{3}$ Ankur Kamra, ${ }^{4}$ Aakash Aggarwal
}

\begin{abstract}
Introduction: The increased risk of morbidity and mortality associated with left ventricular hypertrophy (LVH) diagnosed by electrocardiogram (ECG) or echocardiography is well known. The aim of the study was to evaluate ECG and echocardiography evidence of LVH in patients provisionally diagnosed to have LVH on clinical assessment and to determine the sensitivity and specificity of different criteria of LVH on ECG in comparison with echocardiography.
\end{abstract}

Materials and methods: Hundred patients provisionally diagnosed to have LVH based on clinical assessment were enrolled in this study. A standard 12-lead ECG was recorded. Left ventricular hypertrophy was measured on ECG by applying following criteria: Sokolow-Lyon, Cornell, Romhilt-Estes score. Using two-dimensional echocardiography as the gold standard, LVH was calculated. Sensitivity and specificity of different criteria of ECG were calculated in comparison with echocardiography.

Results: Out of 100 patients suspected to have LVH, 91 patients were found to have LVH on echocardiography. Indicating that echocardiography has sensitivity of $91 \%$ and diagnostic accuracy of $91 \%$. On comparing different criteria, Sokolow criterion was found to have maximum sensitivity of $38.46 \%$, while Cornell criterion was least sensitive, i.e., $14.29 \%$, and sensitivity of Romhilt-Estes criterion was $19.78 \%$. However, overall sensitivity of ECG can be increased by combining all the criteria, i.e., to $45.05 \%$. Specificity of different criteria of ECG was high, i.e., as much as $100 \%$ in case of Romhilt-Estes criterion, while overall specificity of ECG was $77.778 \%$.

Conclusion: Sensitivity and diagnostic accuracy of ECG were very low in comparison with echocardiography in detecting $\mathrm{LVH}$; therefore, ECG cannot replace echocardiography in detecting LVH. Overall sensitivity of different criteria of ECG was low. However, sensitivity of ECG can be increased by combining Sokolow-Lyons voltage criteria and Cornell voltage criteria with Romhilt-Estes point score.

Keywords: Cornell, Echocardiography, Electrocardiogram, Romhilt-Estes score, Sokolow-Lyon.

\footnotetext{
${ }^{1}$ Professor and Head, ${ }^{2}$ Associate Professor, ${ }^{3}$ Junior Resident ${ }^{4}$ Senior Resident

${ }^{1-4}$ Department of Medicine, Sri Guru Ram Das Institute of Medical Sciences \& Research, Amritsar, Punjab, India

Corresponding Author: Gurinder Mohan, Professor and Head, Deparment of Medicine, Sri Guru Ram Das Institute of Medical Sciences \& Research, Amritsar, Punjab, India, e-mail: drgurinder1968@gmail.com
}

How to cite this article: Mohan G, Kaur R, Kamra A, Aggarwal A. A Comparative Study of Electrocardiographic and Echocardiographic Evidence of Left Ventricular Hypertrophy. Curr Trends Diagn Treat 2017;1(2):59-63.

\section{Source of support: Nil}

Conflict of interest: None

\section{INTRODUCTION}

Left ventricular hypertrophy is the thickening of the wall of left ventricle resulting in an increase in left ventricular mass. Left ventricular hypertrophy is a powerful independent risk factor for cardiovascular morbidity and mortality. ${ }^{1}$ The increase in left ventricular mass represents a common final pathway toward the adverse effects on the cardiovascular system and higher vulnerability to complications. ${ }^{2}$ Left ventricular hypertrophy may occur as a result of two basic hemodynamic abnormalities: Systolic overload and diastolic overload. Systolic overload is also known as pressure overload and occurs with conditions like aortic stenosis, systemic hypertension, hypertrophic cardiomyopathy, and coarctation of aorta. Diastolic overload is due to overfilling of left ventricle in diastole so that the left ventricle compromise occurs during diastole. Left ventricular diastolic overload is also known as volume overload, and occurs with mitral incompetence, aortic incompetence, and also with moderate left to right shunt. Echocardiography is considered as gold standard for LVH detection in clinical practice, but ECG remains widely used due to its simplicity, low cost, and easy accessibility. However, ECG criteria for LVH detection exhibit only limited accuracy (generally due to poor sensitivity). ${ }^{3}$ The present study was designed to study various ECG criteria for detection of LVH by comparing it with the gold standard of echocardiography.

\section{MATERIALS AND METHODS}

Hundred patients of either sex more than 18 years of age admitted in emergency, intensive care unit, and medical wards of a tertiary care hospital at Amritsar who were provisionally diagnosed to have LVH based on clinical assessment were enrolled in the study. The patients were 
subjected to ECG and echocardiography to confirm the diagnosis of $\mathrm{LVH}$.

The patients with following etiologies were suspected to have LVH:

- Known cases of hypertension along with minimum of grade I hypertensive retinopathy changes (with or without antihypertensive drugs) ${ }^{4}$

- Atherosclerotic aortic sclerosis

- Rheumatic heart disease with mitral incompetence

- Ischemic cardiomyopathy with mitral incompetence

- Coronary artery disease Following patients were excluded from the study:

- Obese [defined based on body mass index (BMI) $\left.>30 \mathrm{~kg} / \mathrm{m}^{2}\right] .^{5}$

- Smokers

- Patients with physical abnormalities of chest wall, such as kyphosis or scoliosis

- Chronic obstructive lung disease

- Patients manifesting ECG findings of bundle branch block, atrial fibrillation, or atrial flutter and WolffParkinson-White syndrome.

- Patients on digitalis, class 1a antiarrhythmic drugs (i.e., procainamide, quinidine, disopyramide) and class $1 \mathrm{c}$ antiarrhythmic drugs (i.e., flecainide, propafenone) which alter ECG pattern

The study was carried out after approval from hospital ethical committee and after obtaining informed consent from the patient and the relatives. Detailed history was taken regarding the onset of symptoms and presence of risk factors. Detailed general physical examination along with systemic examination including body surface area (BSA) using Mosteller ${ }^{6}$ formula: [BSA $\left(\mathrm{m}^{2}\right)=([$ height $(\mathrm{cm})$ $\times$ weight $\left.(\mathrm{kg})] / 3600)^{1 / 2}\right]$ and BMI using the Quetelet index [weight $(\mathrm{kg}) /$ height $\left(\mathrm{m}^{2}\right)$ ] was calculated.

A standard 12-lead ECG was recorded with subjects lying comfortably in supine position. The machine was calibrated before recording ECG with paper speed $25 \mathrm{~mm} / \mathrm{sec}$ and amplitude of stylus deflection at $1 \mathrm{mV} / \mathrm{cm}$. Left ventricular hypertrophy was measured on ECG by applying following criteria ${ }^{7}$ :

Sokolow-Lyon criterion: S in VI and R in V5 and V6 (whichever is larger) $>35 \mathrm{~mm}$

$\mathrm{R}$ in $\mathrm{aVL}>11 \mathrm{~mm}$

Cornell criteria: $\mathrm{S}$ in V3 and $\mathrm{R}$ in aVL $>28 \mathrm{~mm}$ (men)

$\mathrm{S}$ in $\mathrm{V} 3$ and $\mathrm{R}$ in $\mathrm{aVL}>20 \mathrm{~mm}$ (women)

Romhilt-Estes score: diagnostic $>5$, probable $>4$

Voltage criteria: 3

$\mathrm{R}$ or $\mathrm{S}$ in limb leads: $20 \mathrm{~mm}$

$\mathrm{S}$ in $\mathrm{V} 1$ or $\mathrm{V} 2>30 \mathrm{~mm}$

$\mathrm{R}$ in $\mathrm{V} 5 / \mathrm{V} 6>30 \mathrm{~mm}$

ST/T wave abnormality:

ST/T wave vector opposite to QRS without

digitalis: 3
ST / T wave vector opposite to QRS with

digitalis: 1

Negative terminal $\mathrm{P}$ wave in V1 of $1 \mathrm{~mm}$ in depth and 0.04 seconds in duration indicate left atrial

enlargement: 3

Left axis deviation of QRS of -30 or more: 2

QRS duration $>0.09$ seconds: 1

Delayed intrinsicoid deflection in V5/V6 $>0.05$

seconds: 1

Echocardiography was done with the help of Philips HD 11 XE echocardiogram machine using M-mode, as it has greater resolution due to higher frame rate. ${ }^{8}$ Borders were defined according to proposed criteria given by the American Society of Echocardiography (ASE). ${ }^{9}$ Left ventricular mass was calculated using Devereux's ${ }^{10}$ anatomical validated formula:

$$
\begin{aligned}
& \mathrm{LV} \text { mass }(\mathrm{gm})=0.8\left\{1 . 0 4 \left([\mathrm{LVID}+\mathrm{PWT}+\mathrm{IVST}]^{3}\right.\right. \\
&\left.\left.-[\mathrm{LVID}]^{3}\right)\right\}+0.6 \mathrm{gm}
\end{aligned}
$$

All measurements were made at the end of diastole in centimeters. Left ventricular hypertrophy cut points according to left ventricular mass were taken as $208 \mathrm{gm}$ for men and $145 \mathrm{gm}$ for females ${ }^{11}$ (from Framingham cohort study). Left ventricular mass index (LVM/BSA) was calculated, and cut-off values for LVH for males and females were taken as 108 and $100 \mathrm{gm} / \mathrm{m}^{2}$ respectively ${ }^{12}$ as in Indian Subcontinent. Sensitivity was calculated by dividing true positive by sum of true positive and false negative and then multiplying by 100 .

$$
\text { Sensitivity }=\frac{\text { True positive }}{\text { True positive }+ \text { False negative }}
$$

Specificity was calculated by dividing true negative by true negative and false positive and then multiplying by 100 .

$$
\text { Specificity }=\frac{\text { True negative }}{\text { False positive }+ \text { True negative }}
$$

\section{RESULTS}

Overall in our study, $35 \%(\mathrm{n}=35)$ patients were in age group of 61 to 70 years, $33 \%(n=33)$ were in age group 51 to 60 years, $18 \%(n=18)$ were in age group 41 to 50 years, $9 \%(n=9)$ in 71 to 80 years, $3 \%(n=3)>81$ years, while minimum of $2 \%(n=2)$ in age group of 31 to 40 years. Also, $50 \%(n=50)$ were male and $50 \%(n=50)$ were female. When distributed according to etiology, $98 \%$ $(\mathrm{n}=98)$ of them had hypertension, $14 \%(\mathrm{n}=14)$ had coronary artery disease along with hypertension, $3 \%(n=3)$ had dilated cardiomyopathy with mitral regurgitation $(\mathrm{MR}), 3 \%(\mathrm{n}=3)$ had hypertension with aortic sclerosis, and $2 \%(n=2)$ had rheumatic heart disease with MR. Out of the 100 suspected patients, only $43 \%(n=43)$ patients showed LVH on ECG after applying all the 
A Comparative Study of Electrocardiographic and Echocardiographic Evidence of Left Ventricular Hypertrophy

criteria, while $57 \%(n=57)$ had no evidence of $\mathrm{LVH}$ on ECG. Out of 100 suspected cases, 38\% $(n=38)$ had LVH on ECG after applying Sokolow criterion, $18 \%(\mathrm{n}=18)$ had LVH on ECG with Romhilt-Estes criterion, while $15 \%(n=15)$ had LVH on ECG with Cornell criteria. Out of 100 patients suspected to have LVH, 91 patients were found to have LVH on echocardiography (Table 1). This indicates that echocardiography has sensitivity of $91 \%$ and diagnostic accuracy of $91 \%$ (Table 2). After statistical analysis, sensitivity of ECG (by combining all criteria) turned out to be $45.05 \%$, while specificity of ECG was $77.78 \%$ with a positive predictive value (\%) of $93.35 \%$ and a negative predictive value of $12.28 \%$ (Table 3 ). On comparing individual ECG criteria with echocardiography, sensitivity of Sokolow criterion came out to be $38.46 \%$, and specificity was $66.76 \%$, while positive predictive value was $92.11 \%$, and negative predictive value was $9.68 \%$ (Tables 4 and 5). By comparing RomhiltEstes criterion with echocardiography, sensitivity of Romhilt-Estes criterion in diagnosing LVH was 19.78\%, and specificity was $100 \%$. While positive predictive value was $100 \%$, and negative predictive value was $10.98 \%$ (Tables 6 and 7). By comparing Cornell criterion with

Table 1: Distribution of patients showing LVH on echocardiography

\begin{tabular}{lll}
\hline Echocardiography & Number of patients & Percent \\
\hline LVH & 91 & 91 \\
No LVH & 9 & 9 \\
\hline Total & 100 & 100 \\
\hline
\end{tabular}

Table 2: Sensitivity and accuracy of echocardiography

\begin{tabular}{ll}
\hline Sensitivity & Accuracy \\
\hline $91 \%$ & $91 \%$ \\
\hline
\end{tabular}

Table 3: Sensitivity and specificity of ECG with respect to echocardiography

\begin{tabular}{lllll}
\hline & $\begin{array}{l}\text { Sensitivity } \\
(\%)\end{array}$ & $\begin{array}{l}\text { Specificity } \\
(\%)\end{array}$ & $\begin{array}{l}\text { Positive } \\
\text { predictive } \\
\text { value (\%) }\end{array}$ & $\begin{array}{l}\text { Negative } \\
\text { predictive } \\
\text { value (\%) }\end{array}$ \\
\hline ECG & 45.05 & 77.778 & 95.35 & 12.28 \\
\hline
\end{tabular}

Table 4: Correlation of Sokolow criterion on ECG with echocardiography

\begin{tabular}{lll}
\hline & \multicolumn{2}{c}{$E C H O$} \\
\cline { 2 - 3 } Sokolow criterion & $\mathrm{LVH}$ & No $L V H$ \\
\hline LVH & 35 True positive & 3 False positive \\
No LVH & 56 False negative & 6 True negative \\
\hline
\end{tabular}

Table 5: Sensitivity and specificity of Sokolow criterion with respect to echocardiography

\begin{tabular}{lllll}
\hline & $\begin{array}{l}\text { Sensitivity } \\
(\%)\end{array}$ & $\begin{array}{l}\text { Specificity } \\
(\%)\end{array}$ & $\begin{array}{l}\text { Positive } \\
\text { predictive } \\
\text { value (\%) }\end{array}$ & $\begin{array}{l}\text { Negative } \\
\text { predictive } \\
\text { value (\%) }\end{array}$ \\
\hline $\begin{array}{l}\text { Sokolow } \\
\text { criterion }\end{array}$ & 38.46 & 66.67 & 92.11 & 9.68 \\
\hline
\end{tabular}

Table 6: Correlation of Romhilt-Estes criterion with echocardiography

\begin{tabular}{lll}
\hline & \multicolumn{2}{c}{ ECHO } \\
\cline { 2 - 3 } Romhilt-Estes criterion & LVH & No LVH \\
\hline LVH & 18 True positive & 0 False positive \\
No LVH & 73 False negative & 9 True negative \\
\hline
\end{tabular}

Table 7: Sensitivity and specificity of Romhilt-Estes criterion with respect to echocardiography

\begin{tabular}{lllll}
\hline & $\begin{array}{l}\text { Sensitivity } \\
(\%)\end{array}$ & $\begin{array}{l}\text { Specificity } \\
(\%)\end{array}$ & $\begin{array}{l}\text { Positive } \\
\text { predictive } \\
\text { value (\%) }\end{array}$ & $\begin{array}{l}\text { Negative } \\
\text { predictive } \\
\text { value (\%) }\end{array}$ \\
\hline $\begin{array}{l}\text { Romhilt-Estes } \\
\text { criterion }\end{array}$ & 19.78 & 100.000 & 100.00 & 10.98 \\
\hline
\end{tabular}

Table 8: Correlation of Cornell criterion on ECG with echocardiography

\begin{tabular}{lll}
\hline & \multicolumn{2}{c}{ ECHO } \\
\cline { 2 - 3 } Cornell criterion & LVH & No $L V H$ \\
\hline LVH & 13 True positive & 2 False positive \\
No LVH & 78 False negative & 7 True negative \\
\hline
\end{tabular}

Table 9: Sensitivity and specificity of Cornell criterion with respect to echocardiography

\begin{tabular}{lllll}
\hline & $\begin{array}{l}\text { Sensitivity } \\
(\%)\end{array}$ & $\begin{array}{l}\text { Specificity } \\
(\%)\end{array}$ & $\begin{array}{l}\text { Positive } \\
\text { predictive } \\
\text { value (\%) }\end{array}$ & $\begin{array}{l}\text { Negative } \\
\text { predictive } \\
\text { value (\%) }\end{array}$ \\
\hline $\begin{array}{l}\text { Cornell } \\
\text { criterion }\end{array}$ & 14.29 & 77.778 & 86.67 & 8.24 \\
\hline
\end{tabular}

echocardiography, sensitivity of Cornell in diagnosing LVH was $14.29 \%$ and specificity was $77.778 \%$, while positive predictive value was $86.67 \%$, and negative predictive value was $8.24 \%$ (Tables 8 and 9). However, on comparing individual criterion with each other, Sokolow criterion had maximum sensitivity of $38.46 \%$, while Cornell criterion was least sensitive, i.e., $14.29 \%$, and sensitivity of Romhilt-Estes criterion was 19.78\% (Graph 1);

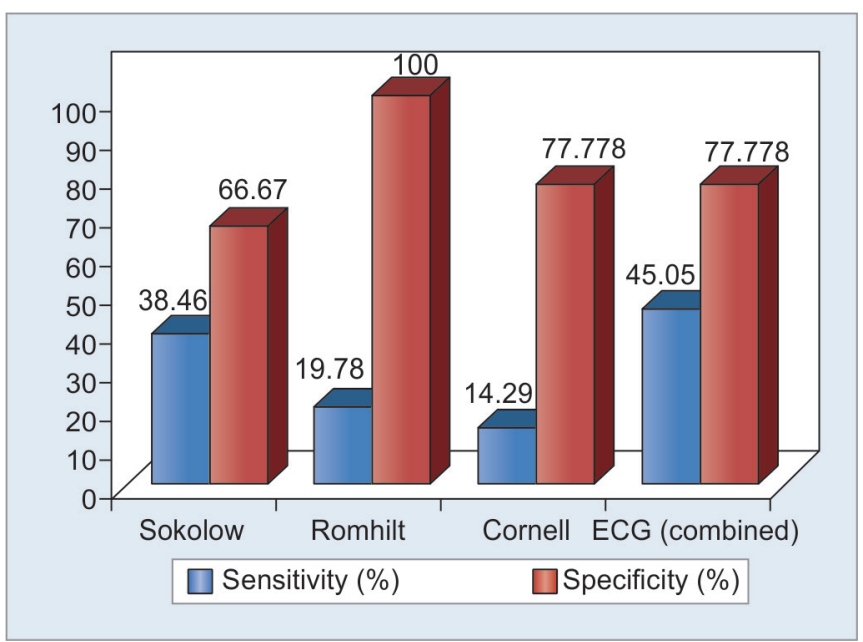

Graph 1: Comparison of sensitivity and specificity of different criteria of ECG 
Table 10: Comparing sensitivity and specificity of different criteria of ECG

\begin{tabular}{lllll}
\hline & $\begin{array}{l}\text { Sensitivity } \\
\text { (\%) }\end{array}$ & $\begin{array}{l}\text { Specificity } \\
(\%)\end{array}$ & $\begin{array}{l}\text { Positive } \\
\text { predictive } \\
\text { value (\%) }\end{array}$ & $\begin{array}{l}\text { Negative } \\
\text { predictive } \\
\text { value (\%) }\end{array}$ \\
\hline Sokolow & 38.46 & 66.67 & 92.11 & 9.68 \\
Romhilt-Estes & 19.78 & 100 & 100 & 10.98 \\
Cornell & 14.29 & 77.778 & 86.67 & 8.24 \\
$\begin{array}{l}\text { ECG (combined } \\
\text { criteria) }\end{array}$ & 45.05 & 77.778 & 95.35 & 12.28 \\
\hline
\end{tabular}

however, overall sensitivity of ECG can be increased by combining all the criteria, i.e., to $45.05 \%$. Specificity of individual criterion of ECG is high, i.e., as much as $100 \%$ in case of Romhilt-Estes criterion (Table 10). The overall specificity of ECG was $77.78 \%$.

\section{Statistical Analysis}

After statistical analysis of different criteria, it is found that Sokolow criterion is better than Cornell and RomhiltEstes criteria in diagnosing LVH with a p-value of 0.001 against Cornell criterion and 0.037 against Romhilt-Estes criterion, which is statistically significant, while no difference was found between Cornell and Romhilt-Estes criteria (Table 11).

\section{DISCUSSION}

In the present study, out of 100 suspected patients echocardiography detected LVH in $91 \%$ of patients with a diagnostic accuracy of $91 \%$, which is consistent with study done by Woythaler et al. ${ }^{13}$ The study showed that echocardiographic left ventricular mass is similar to necropsy obtained left ventricular mass with a correlation coefficient of 0.81 for echocardiography and 0.83 for necropsy data.

In the present study, sensitivity of ECG to diagnose LVH comes out to be $45.05 \%$ and specificity as $77.78 \%$, indicating that ECG is less sensitive in diagnosing LVH which is consistent with many previous studies ${ }^{14-16}$ showing that ECG recognizes LVH poorly with test sensitivity generally ranging from $20 \%$ to below $50 \%$. The study done by Pewsner et $\mathrm{al}^{17}$ also favors present study and found that median sensitivity of ECG to diagnose LVH ranges from 10.5 to $21 \%$ with specificity from 89 to $99 \%$.

In our study, sensitivity of Sokolow criterion to diagnose $\mathrm{LVH}$ came out to be $38.46 \%$, which is consistent

Table 11: Statistical analysis of individual ECG criteria for LVH in comparison with each other

\begin{tabular}{llll}
\hline & $\begin{array}{l}\text { Sokolow vs } \\
\text { Cornell }\end{array}$ & $\begin{array}{l}\text { Sokolow vs } \\
\text { Romhilt-Estes }\end{array}$ & $\begin{array}{l}\text { Cornell vs } \\
\text { Romhilt-Estes }\end{array}$ \\
\hline p-value & 0.001 & 0.037 & 0.243 \\
\hline $\mathrm{S}$ & $\mathrm{S}$ & $\mathrm{S}$ & $\mathrm{NS}$ \\
\hline
\end{tabular}

S: Significant; NS: Nonsignificant with the original study done by Sokolow and Lyon ${ }^{18}$ and Casale et $\mathrm{al}_{1}{ }^{19}$ which shows sensitivity of Sokolow criterion to be 32 and 33\% respectively. Specificity of Sokolow criterion in our study was $92.11 \%$, which is consistent with the work done by Sokolow and Lyon ${ }^{18}$ and Casale et al, ${ }^{19}$ which show the specificities of 100 and 93\% respectively. This indicates that Sokolow criterion is less sensitive in diagnosing $\mathrm{LVH}$.

In the present study, sensitivity of Romhilt-Estes criterion to diagnose LVH was $19.78 \%$, which is consistent with the studies done by Dada et $\mathrm{al}^{20}$ and Okin et $\mathrm{al}^{21}$ which show sensitivities of 18 and $12 \%$ respectively. Specificity of Romhilt-Estes criterion in our study is $100 \%$, which is consistent with the work done by Dada et $\mathrm{al}^{20}$ and Okin et $\mathrm{al}^{21}{ }^{21}$ which show the specificities of 92.80 and $100 \%$ respectively. The study done by Hameed et $\mathrm{al}^{22}$ observed sensitivity and specificity to be 35 and $90 \%$ respectively, indicating that Romhilt-Estes criterion is less sensitive in diagnosing LVH but very specific in diagnosing LVH.

However, sensitivity of Cornell criterion to diagnose $\mathrm{LVH}$ is $14.29 \%$, which is consistent with the studies done by Okin et al ${ }_{,}^{21}$ Domingos et al, ${ }^{23}$ and Dada et $\mathrm{al}^{20}$ in which sensitivities were 22,12 , and $22 \%$ respectively. Our study shows that specificity of Cornell criterion to find LVH is $77.78 \%$, which is consistent with the studies done by Okin et al, ${ }^{21}$ Domingos et al, ${ }^{23}$ and Dada et $\mathrm{al}^{20}$ showing specificities of 87,100 , and $80 \%$ respectively.

In this study, after comparing LVH on ECG in males and females it is found that ECG is more sensitive in males $(51.06 \%)$ vs females $(38.63 \%)$ with a diagnostic accuracy of $52 \%$ in males as compared with diagnostic accuracy of $44 \%$ in females. This finding is consistent with the studies done by Levy et al, ${ }^{11}$ Colossimo et $\mathrm{al}_{1}{ }^{24}$ and Hameed et $\mathrm{al}^{22}$ that ECG is more sensitive in diagnosing LVH, which is perhaps a reflection of higher QRS expression in males.

In the present study, sensitivities of different criteria, Sokolow, Cornell, and Romhilt-Estes, in females were $31.88,11.36$, and $20.45 \%$ respectively. The sensitivities of these criteria in the study done by Casiglia et $\mathrm{al}^{25}$ in females were $12.7,14.6$, and $10.1 \%$ respectively. As sensitivity of Sokolow criterion is maximum, it is better in judging LVH in females, which is consistent with the finding of Alfakih et al showing that Sokolow criterion is better in diagnosing $\mathrm{LVH}$ in females. ${ }^{26}$

In the present study, sensitivities of different criteria, i.e., Sokolow, Cornell, and Romhilt-Estes, in diagnosing LVH in males were $41.68,17.02$, and $19.94 \%$ respectively. The sensitivities of these criteria in the study done by Casiglia et $\mathrm{al}^{25}$ in males were $16.7,3.8$, and $25.5 \%$ respectively.

\section{CONCLUSION}

So, after comparing all these criteria, our study shows that all criteria are very less sensitive in diagnosing $\mathrm{LVH}$, 
with Sokolow criterion showing maximum sensitivity of $38.46 \%$ and Cornell criterion showing minimum sensitivity of $14.29 \%$. But sensitivity can be increased, i.e., up to $45.05 \%$ by using all the criteria to diagnose $\mathrm{LVH}$ in combination. These observations are consistent with the studies done by Dada et $\mathrm{al}_{1}{ }^{20}$ VIIDA study group, ${ }^{27}$ Hammed et al. ${ }^{22}$

After comparing the diagnostic accuracy of all the three criteria with each other, it is found that Sokolow criterion is comparatively better in diagnosing $\mathrm{LVH}$ as compared with Cornell and Romhilt-Estes criteria, which is consistent with the study done by Dada et al, ${ }^{20}$ which also found Sokolow criterion better than other criteria.

\section{REFERENCES}

1. Kannel WB, Levy D, Cupples LA. Left ventricular hypertrophy and risk of cardiac failure: insight from the Framingham study. J Cardiovasc Pharmacol 1987;10(Suppl 6):S153-S140.

2. Devereux RB, Reicheck N. Echocardiography determination of left ventricular mass in men. Anatomic validation of the method. Circulation 1997 Apr;55(4):613-618.

3. Levy D, Labib SB, Anderson KM, Christ JC, Kannel WB, Castelli WP. Determinants of sensitivity and specificity of ECG criteria for left ventricular hypertrophy. Circulation 1990 Mar;81(3):815-820.

4. Chobanian AV, Bakris GL, Black HR, Cushman WC, Green LA, Izzo JL Jr, Jones DW, Materson BJ, Oparil S, Wright JT Jr, et al; National Heart, Lung, and Blood Institute Joint national committee on prevention, detection, evaluation, and treatment of high blood pressure. The Seventh Report of the Joint National Committee on Prevention, Detection, Evaluation, and Treatment of High Blood Pressure: the JNC 7 report. JAMA 2003 May;289(19):2560-2572.

5. Driscoll D, Bistrian B. Parenteral and enteral nutrition in the intensive care unit. In: Irwin R, Rippe J, editors. Intensive care medicine. 2nd ed. Philadelphia (PA): Lippincott Williams \& Wilkins; 2003. pp. 343-345.

6. Mosteller RD. Simplified calculation of body surface area. N Engl J Med 1987 Oct;317(17):1098.

7. Mirvis DM. Electrocardiography. In: Braunwald E, Libby P, Bonow RO, Mann DL, Zipes DP, editors. Braunwald's heart disease a textbook of cardiovascular medicine. 8th ed. Vol. 2. Philadelphia (PA): Elsevier; 2007. p. 164.

8. Foppa M, Duncan BB, Rohde LE. Echocardiography-based left ventricular mass estimation. How should we define hypertrophy? Cardiovasc Ultrasound 2005 Jun;3:17.

9. Sahn DJ, DeMaria A, Kisslo J, Weyman A. Recommendations regarding quantization in M-mode echocardiography: results of a survey of echocardiographic methods. Circulation 1978 Dec;58(6):1072-1083.

10. Connolly HM. Echocardiography. In: Braunwald E, Libby P, Bonow RO, Mann DL, Zipes DP, editors. Braunwald's heart disease a textbook of cardiovascular medicine. 8th ed. Vol. 2. Philadelphia (PA): Elsevier; 2007. pp. 246-296.

11. Levy D, Savage DD, Garrison RJ, Anderson KM, Kannel WB, Castelli WP. Echocardiographic criteria for left ventricular hypertrophy: the Framingham Heart Study. Am J Cardiol 1987 Apr;59(9):956-960.
12. Anis M, Ishaq M, Kundi A, Shah S. Echocardiography correlation of left ventricular mass index in normotensive and hypertensive Pakistani population. Pak J Cardiol 2000;11(1): 9-21.

13. Woythaler JA, Singer SL, Kwan OL, Meltzer RS, Reubner B, Bommer W, DeMaria A. Accuracy of echocardiography versus electrocardiography in detecting left ventricular hypertrophy: comparison with postmortem mass measurements. J Am Coll Cardiol 1983 Aug;2(2):305-311.

14. Holt JH Jr, Barnard ACL, Lynn MS, Svendsen P, Kramer JO Jr. A study of the human heart as a multiple dipole electrical source: II. Diagnosis and quantification of left ventricular hypertrophy. Circulation 1969;40:697-710.

15. Reichek N, Devereux RB. Left ventricular hypertrophy: relationship of anatomic echocardiographic and electrocardiographic findings. Circulation 1981 Jun;63(6):1391-1398.

16. Devereux RB, Phillips MC, Casale PN, Eisenberg RR, Kligfield P. Geometric determinants of electrocardiographic left ventricular hypertrophy. Circulation 1983 Apr;67(4):907-911.

17. Pewsner D, Jüni $P$, Egger $M$, Battaglia $M$, Sundström J, Bachmann LM. Accuracy of electrocardiography in diagnosis of left ventricular hypertrophy in arterial hypertension: systematic review. BMJ 2007 Oct;335(7622):711.

18. Sokolow M, Lyon TP. The ventricular complex in left ventricular hypertrophy as obtained by unipolar and precordial limb leads. Am Heart J 1949 Feb;37(2):161-186.

19. Casale PN, Devereux RB, Kligfield P, Eisenberg RR, Miller DH, Chaudhary BS, Phillips MC. Electrocardiographic detection of left ventricular hypertrophy: development and prospective validation of improved criteria. J Am Coll Cardiol 1985 Sep;6(3):572-580.

20. Dada A, Adebiyi AA, Aje A, Oladapo OO, Falase AO. Standard electrocardiographic criteria for left ventricular hypertrophy in nigerian hypertensives. Ethn Dis 2005 Autumn;15(4): 578-584.

21. Okin PM, Roman MJ, Devereux RB, Borer JS, Kligfield P. Electrocardiografic diagnosis of left ventricular hypertrophy by the time-voltage integral of the QRS complex. J Am Coll Cardiol 1994 Jan;23(1):133-140.

22. Hameed W, Razi MS, Khan MA, Hussain MM, Aziz S, Habib S, Aslam SHM. Electrocardiographic diagnosis of left ventricular hypertrophy: comparison with echocardiography. Pak J Physiol 2005;1(1-2):35-38.

23. Domingos H, Luzio JCE, de Leles GN, Sauer L, Ovando LA. Correlação eletro- ecocardiográfica no diagnóstico da hipertrofia ventricular esquerda. Arq Bras Cardiol 1998 Jul;71(1):31-35.

24. Colossimo AP, de Assis Costa F, Riera AR, Bombig MT, Lima VC, Fonseca FA, Izar MC, Filho BL, Souza D, Povoa RM. Electrocardiogram sensitivity in left ventricular hypertrophy according to gender and cardiac mass. SBC 1992;43:661.

25. Casiglia E, Schiavon L, Tikhonoff V, Bascelli A, Martini B, Mazza A, Caffi S, D’Este D, Bagato F, Bolzon M, et al. Electrocardiographic criteria of left ventricular hypertrophy in general population. Eur J Epidemiol 2008 Mar;23(4):262-271.

26. Alfakih K1, Walters K, Jones T, Ridgway J, Hall AS, Sivananthan M. New gender-specific partition values for ECG criteria of left ventricular hypertrophy: recalibration against cardiac MRI. Hypertension 2004 Aug;44(2):175-179.

27. González-Juanatey JR, Cea-Calvo L, Bertomeu V, Aznar J; for Investigators study VIIDA. Electrocardiographic criteria for left ventricular hypertrophy and cardiovascular risk in hypertensives. VIIDA study. Rev Esp Cardiol 2007 Feb;60(2):148-156. 